\title{
Kajian terhadap Eksistensi Situs Facebook untuk Kepentingan Pelajar Indonesia
}

\author{
Hayadin \\ Peneliti pada Puslitbang Pendidikan, Kementerian Agama RI dan \\ Pemerhati Pengembangan Diri dan Perilaku Pelajar Indonesia
}

\begin{abstract}
Abstrak: Tujuan penelitian ini yaitu untuk mendiskripsikan keberadaan facebook bagi pelajar di Indonesia. Studi ini dilakukan melalui situs media facebook.com secara mendalam dengan berbagai aspek dalam layanan facebook, fitur facebook, platform, tujuan dan sasarannya. Dengan menggunakan metode riviu pada situs facebook, dan buku panduan untuk menerangkan materi dalam facebook, dan juga sumber yang lain yang relevan pada internet dengan menggunakan sumber "google dan yahoo". Hasil studi menunjukkan bahwa facebook dapat digunakan untuk mendukung pembelajaran yang menarik bagi para pelajar terutama dalam hal meningkatkan student social-graph.
\end{abstract}

Kata kunci: facebook, student social graph, generasi jejaring, dan generasi internet.

\begin{abstract}
This research aims to describe facebook existency towards student interestings in Indonesia. Study conducts toward social media site facebook dot com with indeepth aspect on facebook term of services, facebook features, platforms, goals and purposes. Using review method on facebook site itself, and books that explain facebook matters, and also others relevant resources on internet using google and yahoo search engines. The study concludes that facebook could be using to support education and student interestings mainly to enhance student social-graph.
\end{abstract}

Key words: facebook, web 2.0, student social graph, generasi jejaring, and net generation.

\section{Pendahuluan}

Facebook merupakan salah satu situs jejaring sosial atau biasa juga disebut sosial media online (selain myspace.com, linkedin.com, twitter.com) yang memiliki banyak pengguna di dunia, termasuk di Indonesia. Pengguna facebook di seluruh dunia pada tahun 2010 telah mencapai 400 juta orang lebih dan di Indonesia telah mencapai 19.094.640 per 1 Maret 2010 (http://petamasadepanku.net: 2010). Jumlah tersebut meningkat 1.792.880 orang selama kurun waktu 1 Februari hingga 1 Maret 2010 (http://www.insidefacebook.com: 2010). Salah satu penyebabnya yaitu karena bahasa Indonesia menjadi salah satu bahasa yang dipakai oleh facebook sejak tahun 2008, sehingga mendorong banyak orang termasuk pelajar dan anak-anak (yang tidak tahu bahasa Inggris) yang melek internet membuat akun di facebook.com. Perkembangan tersebut membawa implikasi yang luas karena sebagian masyarakat dan pengguna belum atau tidak memahami secara mendalam keberadaan facebook sebagai situs jejaring sosial yang bersifat publik, terbuka, dan instan. Pada awal facebook populer di Indonesia, beberapa pihak menolak dan bersikap kontra terhadap facebook. Sikap tersebut dilandasi oleh pertimbangan dampak negatif yang muncul dari penggunakan (penyalahgunaan) facebook (http:/ Lpetamasadepanku.net: 2008). Pada beberapa bulan terakhir, media massa melansir beberapa kasus penyalahgunaan situs facebook.com (http:/ Lwww.inilah.com: 2010) yang melibatkan pelajar, dan juga orang dewasa. Hal tersebut secara sederhana merupakan akibat dari kekurangtahuan pengguna terhadap eksistensi dan manfaat facebook. Salah satu kasus facebook dengan nama akun Ari Power yang membawa kabur seorang pelajar perempuan yang dikenalnya melalui facebook (http://www.surya.co.id: 2010).

Kasus ini membuat kaget dan prihatin banyak kalangan terutama para orang tua, pendidik (guru, kepala sekolah, konselor), psikolog serta pemerhati media. Para orang tua kaget, karena mungkin baru menyadari bahwa facebook dapat dijadikan sebagai sarana penculikan anak-anak. Mereka sangat khawatir kasus tesebut terjadi pada anak- 
anak mereka. Para pendidik juga kaget karena peristiwa tersebut berada diluar dugaan dan baru pertama kali terjadi. Bahkan bagi sebagian pendidik yang belum melek teknologi informasi (khususnya internet) memandang hal tersebut sebagai diluar wawasan mereka. Demikian pula, para pengamat media informasi yang menyadari sepenuhnya dan mengetahui dampak negatif dari sebuah wadah komunikasi publik tanpa batas seperti internet.

Berdasarkan sejarahnya, facebook pertama kali diluncurkan dan digunakan untuk menjalin pertemanan bagi para pelajar di Los Angeles. Karena sifat internet yang tanpa batas, maka kemudian facebook berkembang ke seluruh dunia, dengan fungsi dan tujuan utama untuk menyambung kekerabatan.

Banyak masyarakat (termasuk pelajar) yang kurang tepat dalam menggunakan situs facebook untuk menjalin silaturahmi dan untuk tujuan pendidikan. Banyak pula pelajar yang terpengaruh (baik secara sadar ataupun tidak sadar) oleh berbagai komunitas, pengguna lain, group, ataupun oleh fitur-fitur yang tersedia di dalam situs facebook.com. Oleh karena itu, masyarakat terutama pelajar perlu mendapatkan pencerahan tentang apa dan bagaimana menggunakan facebook secara baik. Pelajar perlu mengetahui bahwa situs facebook dapat digunakan untuk mendukung kepentingan pendidikan dan pembelajaran (http://petamasadepanku.net: 2008).

Penelitian ini berusaha untuk mendeskripsikan secara lebih dalam dan singkat tentang eksistensi facebook, kebijakan privasi facebook, fungsi aplikasi dan fitur-fitur yang dimiliki oleh facebook.com. Karena sebagai media dan teknologi komunikasi dan informasi yang canggih, facebook sama dengan perangkat iptek lainnya yang memiliki potensi ganda yakni dapat digunakan untuk tujuan positif dan dapat pula digunakan untuk tujuan negatif. Untuk itu maka penelitian ini berusaha untuk mereview situs facebook.com secara singkat dan komprehensif.

Masalah dalam penelitian yaitu Apakah keberadaan facebook seperti yang tertuang dalam tujuan, kebijakan privasi, aplikasi, dan fiturnya relevan dengan kepentingan pelajar?

Atas dasar rumusan masalah tersebut, maka penelitian ini bertujuan untuk mengetahui rele- vansi keberadaan facebook bagi kepentingan pelejar sesuai dengan tujuan, kebijakan privasi, aplikasi dan fitur yang dimiliki oleh facebook.com.

\section{Kajian Litratur \\ Internet dan Pelajar Indonesia}

Secara umum, pelajar adalah penduduk usia muda yang memiliki karakteristik dinamis, dan maju, serta memiliki rasa ingin tahu yang besar (curiousity) terhadap lingkungan disekitarnya termasuk perkembangan teknologi. Don Tapscott seperti dikutip oleh Tilaar (2000: 7), menyebut kelompok generasi muda (pelajar) dengan istilah Net Generation, yakni kelompok generasi muda yang kehidupannya sangat dipengaruhi oleh teknologi informasi sehingga memiliki perilaku berbeda dengan generasi tua.

Net-Generation yang berarti generasi jejaring, adalah istilah yang diberikan kepada generasi muda yang hidupnya sangat akrab dan dipengaruhi oleh teknologi informasi dan komunikasi dengan membentuk jaringan (net) yang luas ke seluruh penjuru dunia. Mereka ini sejak lahir, tumbuh dan berkembang di tengah budaya global yang diwarnai oleh penggunaan teknologi komunikasi dan informasi. Sejak kecil mereka telah mengenal dan menikmati media televisi, telepon dan handphone. Hampir seluruh aspek kehidupan $N$-Gen melibatkan unsur teknologi, seperti: telepon, handphone, komputer, internet, dan alat hiburan elektronik seperti game (permainan), tape recorder, dan teknologi digital lainnya.

Menurut Don-Tapscott (dalam Tilaar, 2007) the Net-Generation atau biasa disebut dengan singkatan $\mathrm{N}$-Gen adalah generasi internet yang lahir pada dua dasawarsa terakhir. Gaya hidup mereka yang berbeda dengan generasi sebelumnya dapat dilihat pada cara belajar, dan berkomunikasi. Hampir seluruh aktifitas komunikasi mereka baik dibidang sosial ataupun ekonomi, dan cara belajarnya, melibatkan teknologi informasi. Fasilitas short message sending (SMS), chatting, search engine, group-discuss, tele-conference, VCD, games, menjadi bagian dari gaya dan cara hidup mereka.

Don Tapscott (dalam Tilaar, 2007) menyebutkan beberapa sikap dari $\mathrm{N}$-Gen adalah berpikir bebas, keterbukaan emosional dan intelektual, inklusif, kebebasan berekspresi, inovatif, matang, 
investigatif, kekinian, peka terhadap pengaruh korporasi, jujur dan penuh percaya diri. Karakter mereka yang khas adalah individualis dan rasa ingin tahu (curiousity) yang tinggi. Hal tersebut sebagai konsekwensi dari bentukkan lingkungan yang serba digital.

Di samping pengaruh lingkungan digital, faktor internal psikologis manusia juga memberikan andil yang besar terhadap lahirnya perilaku generasi jejaring (Net Generation). Menurut Dimitri Mahayana (1999: 9), era informasi terjadi karena ada suatu hasrat primordial manusia untuk berkomunikasi satu sama lain, tanpa batasan kelas, tanpa batasan ras, tanpa terlintas oleh mahalnya biaya, tanpa dikendalikan oleh penguasapenguasa masyarakat yang sering memotong dan mengarahkan informasi dengan kepentingan melanggengkan kekuasaannya. Martinez (2010: 79) juga mengemukakan tentang karakter generasi muda bahwa "Younger generation is having a huge impact as they indulge in the very natural human need to share, collaborate, learn and contribute together as a group with common needs, interests and experiences".

\section{Facebook dan Kepentingan Pelajar}

Pada awal facebook yang didirikan oleh Mark Zuckerberg bersama rekannya di Harvard University, keanggotaan hanya untuk mahasiswa Universitas Harvard. Kemudian diperluas ke beberapa perguruan tinggi lain di Boston, Universitas Stanford, dan Liga Ivy. Pada saat ini, facebook dapat diakses oleh siapa saja yang berusia 13 tahun ke atas. Saat ini, situs facebook memiliki lebih dari 400 juta pengguna aktif di seluruh dunia (http://en.wikipedia: 2010).

Nama facebook berasal dari nama buku yang diterbitkan Universitas yang didistribusikan kepada seluruh mahasiswa dan berisi wajah seluruh sivitas akademika yang diberi nama face book. Facebook sendiri secara semantik berarti 'buku wajah', artinya buku yang berisi foto wajah seluruh sivitas akademik Universitas Harvard.

Pengguna facebook pada saat ini berjumlah kurang lebih 400 juta orang dan akan terus bertambah. Rata-rata pengguna memiliki teman sebanyak 250 orang di facebook. Setiap hari 5 juta menit terkoneksi ke facebook; dan sebanyak 30 juta pengguna mengapdate status mereka setiap hari. Sebanyak 8 juta pengguna bergabung pada halaman facebook (facebook fun/page) setiap harinya. Facebook diterjemahkan kurang lebih 50 bahasa negara di dunia termasuk bahasa Indonesia dan akan terus bertambah, dan lebih dari 70\% pengguna berada di luar negara Amerika Serikat, tempat dimana markas Internasional facebook corporation berkantor (Maver: 2010; 3-4).

Dengan jumlah anggota jejaring yang besar tersebut, maka dalam perspektif pendidikan facebook memiliki potensi yang besar (positif dan/ atau negatif) terhadap kepentingan pelajar. Freishtat dan Sandlin $(2010 ; 148)$ menyebutnya sebagai public pedagogy. Demikian pula, Buckley $(2010$; 118) yang menemukan fakta bahwa facebook sebagai salah satu Web 2.0 merupakan sarana belajar bersama (collborative learning), "By using Web 2.0 technologies, students are able to collaborate at distance, at a time that suits them".

Oleh karena itu, kehadiran facebook sebagai salah satu situs jejaring sosial di dunia maya, merupakan perwujudan dari fenomena generasi jejaring ( $\mathrm{N}$-gen) dengan menggunakan internet. Demikian pula dengan hasrat besar dari anak muda untuk membuat akun dan berpartisipasi dalam situs tersebut. Besarnya jumlah pelajar Indonesia yang memiliki akun di facebook dan situs jejaring sosial lainnya, merupakan salah satu bukti bahwa pelajar Indonesia merupakan bagian dari generasi jejaring dunia (global net generation) yang dapat menerima dampak atau mengambil manfaat dari facebook.

\section{Metodologi Penelitian}

Penelitian ini dilaksanakan dari bulan Januari sampai Mei 2010 di Jakarta. Metode Penelitian menggunakan pendekatan kualitatif. Berdasarkan tujuan dan sasarannya, maka penelitian ini merupakan tinjauan atau review terhadap website. Instrumen pengumpulan data dalam penelitian ini adalah internet dengan menggunakan akun facebook dot com, dan fasilitas pencarian (facebook Search Engine) Google search dan Yahoo search. Analisis data dilakukan secara interpretative, komparatif, dan depth studies terhadap berbagai informasi yang relevan yang terdapat pada berbagai situs di internet dan terutama yang terkait dengan tujuan penggunaan facebook untuk kalangan pelajar. 


\section{Obyek Penelitian/sumber data}

Obyek penelitian adalah situs facebook yakni http:/ Lwww.facebook.com/. Sumber data berasal dari situs utama facebook.com dan situs lainnya yang relevan seperti wikipedia dan artikel lainnya di internet, yang diperoleh melalui search engine google dan yahoo. Selain melalui situs internet, data dan informasi juga diperoleh melalui berbagai buku literatur yang membahas tentang facebook.com

\section{Teknik Pengumpulan data}

Data utama penelitian yang berasal dari situs facebook.com dikumpul dengan menggunakan akun facebook peneliti. Setelah login, beberapa data yang relevan dikumpulkan, kemudian disortir dan disajikan secara naratif dan deskriptif. Penelusuran data dilakukan melalui teknik searching melalui fasilitas searching facebook, Google search dan Yahoo search.

\section{Validitas Data}

Untuk menjamin validitas data maka dilakukan check informasi secara berulang-ulang dari situs facebook dan membandingkannya dengan informasi yang diperoleh dari situs lain seperti: wikipedia.com, serta situs lainnya yang diperoleh melalui mesin pencari google.com, dan yahoo.com. Selain itu juga beberapa buku-buku literature yang membahas tentang sosial media khususnya tentang facebook.com.

\section{Hasil Penelitian dan Pembahasan Ketentuan Dasar Penggunaan Facebook}

Setiap pengguna facebook harus menyetujui persyaratan dan ketentuan yang ditetapkan oleh facebook. Ketentuan tersebut terbuat dalam Facebook's Privacy Policy (http://www.facebook. com, 2010), yang terdiri atas 9 item, yakni sebagai berikut: Introduction, Information We Receive, Sharing information on Facebook, Information You Share With Third Parties, How We Use Your Information, How We Share Information, How You Can Change or Remove Information, How We Protect Information, dan Other Terms.

Secara sederhana, beberapa point penting dari kebijakan privasi facebook, tersebut adalah sebagai berikut: 1) Anak berusia di bawah 13 tahun, dilarang mendaftar dan mengirimkan informasi dirinya ke facebook. Jika ketahuan akunnya akan dihapus secara sepihak oleh facebook. Partisipasi orang tua dalam mendampingi anak-anak (minors 13 tahun) yang mendaftar ke facebook merupakan hal yang wajib. Orang tau harus tahu materi yang dikirimkan (posting) anaknya ke internet); 2) Informasi yang diberikan (oleh pengguna) kepada facebook terdiri atas: biodata (informasi tentang diri), konten, informasi teman, informasi situs, browser yang digunakan, cookies, dan lain-lain. Informasi tentang diri pengguna (biodata ketika mendaftar) meliputi antara lain: nama, email, jenis kelamin, dan tanggal lahir. Pengguna juga dapat menambahkan pasphoto atau gambar diri. Dalam beberapa kasus facebook akan meminta informasi tambahan untuk alasan keamanan atau untuk menyediakan layanan khusus kepada pengguna. Setelah mendaftar, pengguna dapat memberikan informasi tambahan tentang dirinya tentang hal-hal sebagai berikut: kota tempat tinggal saat ini, kota asal, keluarga, jaringan kerja, aktivitas, minat, seerta pandangan politik dan keagamaan. Konten, meliputi antara lain: status Anda, foto, video, links (anchor teks), membuat kegiatan (events) atau kelompok, membuat komentar, menulis sesuatu pada wall seseorang, menulis atau mengirim pesan pada seseorang. Facebook juga menghimpun berbagai informasi tentang pengguna ketika berinteraksi dengan Facebook, yakni antara lain: Informasi aktivitas situs. Seperti menambah koneksi (termasuk bergabung dengan kelompok atau menambahkan teman), membuat album foto, mengirim hadiah, menghadiri event, atau menggunakan aplikasi tertentu di facebook; Cookie Informasi yakni potongan-potongan kecil data yang disimpan oleh facebook untuk jangka waktu tertentu pada komputer pengguna, ponsel, atau perangkat lain. Facebook menggunakan cookies untuk mengkonfirmasi bahwa pengguna login ke facebook, dan mengetahui kapan pengguna berinteraksi dengan aplikasi facebook, platform, dan iklan facebook; 3) Facebook menggunakan informasi yang dikumpulkan dari pengguna untuk memberikan layanan yang sesuai, aman, dan efisien, yakni antara lain: untuk menghubungi pengguna terkait dengan perbaikan layanan facebook, untuk menyediakan iklan yang sesuai kepada pengguna (to serve personalized advertising 
to you), untuk melengkapi profil pengguna (to supplement your profile), membuat saran (to make suggestions), dan menawarkan perangkat lunak yang cocok untuk didonlot (downloadable software); 4) Secara khusus, facebook meminta penggunanya untuk mengatur privasi, sebelum berbagi informasi di facebook. Beberapa aspek yang penting untuk diatur antara lain: nama dan gambar profil, kontak informasi, informasi pribadi, posting pribadi (Posts by Me), koneksi, gender dan tanggal lahir, informasi untuk "semua orang", anak di bawah umur. Facebook juga meminta agar melaporkan setiap pelanggaran keamanan (report violations); dan 5) Pada bagian akhir, Facebook menyatakan bahwa sewaktu-waktu dapat merubah Kebijakan Privasinya sesuai dengan prosedur yang ditetapkan.

Meskipun kebijakan privasi facebook telah dirancang dan disusun untuk melindungi kerahasiaan dan kenyamanan penggunanya, tetapi beberapa pengguna facebook merasa keberatan dan memandang hal-hal berikut sebagai mengurangi kebebasan dan kerahasiaan pengguna, yakni antara lain: 1) Seluruh informasi tentang pengguna dan informasi teman-teman pengguna akan terakses pada berbagai aplikasi facebook yang diinstall. Artinya pemilik applikasi di facebook dibolehkan untuk secara langsung mengakses informasi terhadap pengguna facebook; 2) Seluruh informasi dan komentar yang ditulis di Wall (dinding facebook) serta aplikasi yang digunakan oleh pengguna akan tersebar kepada pengguna lainnya melalui fasilitas NewsFeed; 3). Aplikasi facebook beacon, akan menginformasikan apa yang dibeli (belanja) pengguna melalui facebook, meskipun pengguna tersebut tidak ingin pengguna lainnya mengetahui barang apa yang dibeli (Alba: 2008; 47 -48).

\section{Fitur dan Aplikasi Facebook}

Secara sederhana navigasi Facebook memberikan kemudahan kepada pengguna untuk mengakses fungsi situs dan fitur serta aplikasi yang dikembangkannya. Fitur dan aplikasi yang ada di facebook berjumlah kurang lebih 350.000 aplikasi (active applications) dan akan terus bertambah (Maver: 2010; xvi). Beberapa aplikasi yang terdapat di facebook yaitu profil, yang memiliki tempat yang menonjol di bagian atas halaman situs pengguna. Pengamat facebook menyebutnya sebagai "the center of facebook" (Barefoot: 2010; 174). Fitur lainnya adalah: Wall, Newsfeed, Notes, Foto, Catatan, Groups, Acara dan item Posted, dan lain-lain (http://en.wikipedia: 2010). Berbagai fitur dan aplikasi tersebut senantiasa berubah dan berkembang setiap saat, sesuai dengan perkembangan teknologi serta inovasi yang dilakukan oleh perusahaan Facebook dan penggunanya.

Wall merupakan fitur yang paling banyak digunakan yakni ruang di halaman profil pengguna yang dapat digunakan untuk mengekspresikan pikiran serta menulis status berisi pesan, pandangan, perasaan, kesan dan lain-lain. Wall tersebut dapat dilihat oleh oleh semua temanteman pengguna di facebook, serta dapat pula memberikan komentar dan tanggapan terhadap apa yang ditulis oleh seseorang.

News feed adalah fitur facebook yang dikembangkan oleh Farooq Khan yang memungkinkan status pengguna (apa yang ditulis publisher) dan profilnya dapat diketahui oleh temannya di facebook. Karena fungsi tersebut, fitur Newsfeed banyak dimanfaatkan oleh pengguna terutama para spammer untuk membuat status palsu dalam rangka mengganggu pengguna lainnya. Fakta tersebut membuat facebook memperbaiki fungsi fitur newsfeed sehingga dapat diatur sesuai kehendak dan privasi pengguna. Ini merupakan fitur yang melahirkan pro-cons (setuju-tidak setuju) terhadap kebijakan privasi facebook (Alba: 2010).

Status, yang memungkinkan pengguna untuk menginformasikan keberadaannya serta aktivitas yang sedang dilakukannya kepada teman-temannya. Hal ini tergantung pada pengaturan privasi, siapa saja yang dapat melihat profil pengguna. Fitur Chat memungkinkan pengguna facebook berinterkasi secara langsung. Pengguna hanya boleh berinteraksi (chat) dengan satu orang pengguna (a one to one basis) dan dapat secara simultan dapat membuka halaman chat lebih dari satu untuk berinteraksi dengan teman yang lain tanpa melibatkan teman lain (separate chat interface).

Foto, di mana pengguna dapat meng-upload album dan foto. Pengguna dapat meng-upload album dan foto untuk jumlah yang tidak terbatas. Melalui pengaturan privasi album foto dapat diatur untuk album individu, dan membatasi pengguna 
lain untuk dapat melihat album. Fitur lain dari aplikasi Foto adalah kemampuan untuk "tag", atau label pengguna di foto. Misalnya, jika foto berisi teman pengguna, maka pengguna dapat menandai teman dalam foto. Melalui fitur ini teman mereka diberitahu link untuk melihat foto.

Pokes, yang memungkinkan pengguna untuk mengirim poke "virtual" satu sama lain (pemberitahuan kemudian memberitahu pengguna bahwa mereka telah menusuk); Hadiah yang memungkinkan pengguna untuk mengirim hadiah virtual kepada teman-teman mereka.

Events adalah fitur yang dapat digunakan oleh pengguna untuk menginformasikan suatu kegiatan seperti: seminar, lokakarya, bedah buku, gathering keluarga, reuni alumni, yang disiapkan untuk dihadiri oleh teman-teman atau komunitasnya. Untuk membuat events di facebook, perlu mencantumkan nama events, nama pihak penyelenggara, jenis kegiatan, siapa saja yang boleh hadir, kapan mulai dan berakhirnya event. Suatu event dapat diatur menjadi terbuka, tertutup, atau rahasia.

Selain membuat events, pengguna facebook dapat pula membuat groups dan like pages atau Fun pages untuk menghimpun teman-temannya yang memiliki persamaan minat dan ketertarikan terhadap produk barang dan atau jasa, tokoh ilmuwan, pandangan politik dan filsafat, agama atau aliran kepercayaan, bahkan mata pelajarana tertentu. Groups dapat digunakan secara dinamis, dialektis dan interaktif, untuk berdiskusi terhadap isu tertentu. Sementara Like pages atau Fun pages lebih bersifat monoton dan monolog. Vander Veer (2010; 107) menyebutnya sebagai fitur yang paling populer. "One of Facebook's most popular features is Groups-collections of people who share interests. Some Groups exist only online, but some real-world groups use Facebook to keep in touch". Kelsey $(2010$; 29) mengemukakan fungsi Group sebagai berikut: "Groups provide a common area for discussion, pictures, and the latest news. Facebook also makes it very easy to create your own group". Artinya, group (salah satu fitur facebook) menyediakan tempat bagi public untuk berdiskusi, berbagi informasi dan berita atau gambar.

\section{Penyalahgunaan Facebook}

Selain penggunaan facebook seperti yang diharap- kan oleh penciptanya (Mark Zuckerberg dan kawan-kawan), situs ini juga banyak disalahgunakan oleh pihak-pihak yang memiliki kepentingan dan perilaku negative. Petti Lubis dan Mutia Nugraheni (http://id.news.yahoo.com: 2010) menulis bahwa beberapa kejahatan (perilaku negative) di facebook.com antara lain: membuat profil palsu, memanipulasi penampilan; menulis status berlebihan dan provokatif; memasang foto ambigu; hubungan palsu.

Secara Internasional, dilaporkan bahwa telah terjadi penyalahgunaan facebook dalam hal, sebagai berikut: hosting pro-anoreksia dan proinformasi bulimia; Penyalahgunaan Pengiklan; Cyberbullying (http://en.wikipedia, 2010). Akibat dari banyaknya penyalahgunaan facebook untuk tujuan kejahatan, maka beberapa kelompok melakukan sensor kepada facebook.com. Beberapa nengara yang memperlakukan sensor kepada situs facebook.com adalah: Syiria, Burma, Bhutan, Iran dan Vietnam, Cina.

Beberapa organisasi dan perusahaan juga memblokir facebook. Departemen Pendidikan dan Pelatihan New South Wales juga telah memblokir semua pengguna (mahasiswa dan staf) dari mengakses Facebook, seperti yang banyak departemen pemerintah lainnya di Australia. Kota New York Departemen Kesehatan dan Rumah Sakit blok Facebook dari penggunaan di tempat kerja.

Selain organisasi dan perusahaan, ada pula sekolah dan kampus yang memblokir akses ke situs facebook.com. University of New Mexico (UNM) pada Oktober 2005 memblokir akses ke Facebook dari jaringan komputer kampus. Dalam sebuah pesan kepada siswa yang mencoba untuk mengakses situs facebook dari jaringan kampus, muncul tulisan, "Situs ini sementara tidak tersedia saat UNM dan pemilik tempat kerja keluar masalah prosedural. Situs ini (facebook) melanggar UNM's Acceptable Komputer Use Policy. Terkait dengan siswa, bagi yang terbukti memposting materi ilegal atau tidak pantas, mereka akan menghadapi tindakan disiplin dari perguruan tinggi mereka, termasuk pengusiran.

Sebuah penelitian tentang penggunaan facebook dikalangan mahasiswa pendidikan tinggi menunjukkan bahwa ada manfaat yang diperoleh mahasiswa dari facebook antara lain terhadap tingginya kehadiran di sekolah, silaturahim, 
mengurasi rasa tertekan, kesepian, dan kerinduan terhadap keluarga; dan ada pula hasil riset yang menemukan hasil bahwa siswa yang menggunakan facebook memiliki nilai rata-rata yang lebih rendah dibandingkan dengan siswa yang tidak memiliki akun facebook.

Berdasarkan uraian sejarah singkat seperti tersebut di atas, dapat diketahui bahwa situs jejaring sosial facebook diciptakan oleh seoran pelajar (mahasiswa tingkat awal) dengan maksud agar setiap mahasiswa dapat saling mengenal. Hal tersebut dilakukan melalui tampilan identitas nama dan foto yang dipampang pada halaman situs. Meskipun pada awalnya hanya diperuntukkan bagi mahasiswa di Universitas Harvard Amerika Serikat, tetapi karena sifat dari media internet yang tanpa batas (mondial), maka kini seluruh negara dapat mengaksesnya secara mudah. Bukan hanya pelajar, seperti pada awal diciptakannya, para tokoh dunia juga menggunakan dan memiliki akun facebook sebagai alat untuk bersosialisasi dan menyebarkan pesan dan pandangan-pandangannya.

Disamping tokoh dunia yang menggunakan untuk tujuan yang baik, di facebook juga ada orang-orang tertentu yang menggunakan dan membuat akun facebook untuk tujuan yang tidak baik, misalnya: untuk menyebarkan berita yang menyesatkan, dan menyebarkan pornografi. Oleh karena itu, anak-anak yang berusia 13 tahun atau kurang dari 13 tahun dilarang menggunakna facebook, seperti dijelaskan dalam kebijakan privasi facebook.com. Selain melarang anak dibawah umur (13 tahun) facebook juga meminta perhatian orang tua agar mengawasi anak-anak yang menggunakan facebook agar terhindar dari perilaku usil pihak lain. Orang tua diminta untuk tahu apa yang dilakukan oleh anak pada saat berfacebook.

Sebagai media komunikasi dan jejaring sosial online, facebook memiliki potensi besar untuk dimanfaatkan oleh penggunanya dalam mengekspresikan, mengkomunikasikan, dan berinteraksi secara masal dan global dengan berbagai bahasa dan bentuk. Pengguna dapat mengekspresikan pikiran, pandangan, sikap, bahkan keinginannya melalui tulisan, gambar, video, bahkan dengan sekedar memberi sinyal (poke atau huge).

Pengguna dapat mencari teman dan keluarga setelah sekian lama tidak bertemu, hanya dengan mengetik nama, sekolah, daerah asal, atau tempat tinggal. Silaturahmi dapat dijalin lebih akrab melalui surat-suratan (secara elektronik), bahkan bertukar pikiran secara langsung melalui fasilitas chating yang ada di facebook. Sebaliknya untuk hal yang negatif, pengguna juga dapat menghina bahkan mencacimaki pengguna lainnya melalui facebook. Salah satu yang dikeluhkan oleh pemilik facebook pada awal peluncurannya adalah munculnya perilaku buliying melalui facebook. Orang dapat menyerang, menghina, mencaci pengguna lainnya secara bebas dan anonym (akun dengan nama palsu) tanpa ditindak secara hukum.

Kehadiran facebook melahirkan jejaring pertemanan baru di dunia maya. Seseorang yang aktif ber facebook biasanya mempunyai teman yang banyak. Hal tersebut mengandung arti bahwa pengguna tersebut memiliki relasi dan jaringan sosial seperti tergambar pada statistik profile penggunanya. Meskipun bersifat maya, tetapi jejaring dan relasi tersebut memiliki potensi real untuk teraktualisasi. Para ahli menyebut fenomena ini dengan istilah 'online sosial graph' (Shih, Clara Chung-wai: 2009; 11).

Online Sosial Graph adalah peta jaringan dan hubungan seseorang dengan pengguna lainnya di Internet. Secara lebih gamblang Shih, Clara Chung-wai $(2009 ; 3)$ menyebutkan bahwa

"the online sosial graph-that is, the mapof every person on the Internet and how they are connected. It is the World Wide Web ofpeople, a reflection and extension of the offline sosial graph-the friends, family members, colleagues, mentors, classmates, neighbors, and acquaintances who are important to us, who help shape us, and for whom we live. The online sosial graph empowers us to be better, more effective, more efficient, and more fulfilled doing what is inherent to our nature-communicating who we are, and transacting and interacting with others across the Web.

Untuk tujuan pendidikan dan pembelajaran, maka para pengguna facebook terutama pelajar dapat dengan mudah berkomunikasi, menambah teman (add friend) dan membentuk Group (kelompok diskusi online) berdasarkan minat dan topik yang diinginkan dan disepakati untuk memperluas Online Sosial Graph. Pengguna hanya perlu membuat kelompok/group yang aplikasinya 
telah disediakan oleh facebook.com. Selanjutnya, setiap orang yang menjadi anggota group dapat mengemukakan pandangan tentang suatu topik yang sedang dibahas. Dapat pula group tersebut dibuat berdasarkan kesamaan minat atau cita-cita atau orientasi karier dan masa depan. Semuanya sangat terbuka dan bebas. Setiap orang dapat membuat group dan mengundang teman-temannya untuk bergabung menjadi anggota. Selain membuat group, para pengguna juga dapat membuat 'Like/Fun Page" di facebook, yakni suatu halaman yang dibuat dan ditujukan untuk organisasi pelajar/pemuda, tokoh idola, pahlawan.

Jason Alba (2010; 54 - 56) mengemukakan beberapa manfaat facebook yang dapat diperoleh pelajar, yakni: menemukan teman sekelas untuk belajar bersama tentang suatu topik tertentu (find classmate); berkomunikasi dengan guru atau dosen bahkan dengan professor (Communicae with Your Professor); Berkolaborasi dengan teman sekelas dalam suatu group tertentu (Collaborate with classmates). Sejalan dengan hal tersebut Carolyn Abraham (2010; 21 - 23) menambahkan bahwa Pelajar menggunakan facebook untuk berbagai kebutuhan praktis, seperti: memperoleh informasi (Getting information) dengan mudah tentang kawan dan keluarga. Merencanakan kegiatan (planning events); Berbagi informasi dan komentar tentang foto-foto kegiatan (tagging photos); mencari pekerjaan (getting a job); mengetahui kegiatan teman (finding activity partners). Beberapa aplikasi yang cocok dan mendukung kepentingan pelajar adalah sebagai berikut: Class Talk, Share Homework, Class Point, The Cheap Textbooks Application, Tutor Application, Rate Teacher Application (Alba; 2010). Dalam rangka memetik manfaat dari facebook, maka sebaiknya pelajar (pengguna) merumuskan tujuan tertentu dalam menggunakan facebook (in advance what your facebook goals are) (Alba; 2010).

Salah satu tujuan yang mungkin dapat dirumuskan dari penggunaan facebook (contoh) adalah untuk mendukung kesuksesan studi dan pendidikan. Untuk mendukung tujuan tersebut, maka beberapa hal dapat dilakukan seperti: menambah teman (add friends) pelajar yang memiliki gagasan dan cita-cita profesi yang sejenis, atau mencari (search friends) dan menambah teman (senior) yang sukses, bahkan menambah- kan tokoh ilmuwan, praktisi yang professional untuk menjadi mentor dan membantu kesuksesan studi dan pendidikan. Selain itu, dapat pula dengan menggabungkan diri pada beberapa group yang sesuai dengan minat dan cita-cita, atau yang membahas disiplin ilmu yang digeluti.

Untuk menjaga keamanan dan kenyamanan dalam menggunakan facebook dapat dilakukan dengan mengatur privasi pengguna. Pengaturan privasi memberikan pilihan kepada pengguna apakah akan memperlihatkan profilnya (termasuk: identitas kelahiran, nomor handphone, email, agama, aliran politik, dan lain-lain) kepada publik atau kepada temannya saja; apakah akan memperlihatkan statusnya yang ditulis di Wall kepada publik, temannya saja, atau tidak kepada siapapun; apakah akan menampilan video dan gambar yang diposting kepada publik, atau kepada temannya saja, atau tidak kepada siapapun selain dirinya. Melalui pengaturan privasi kita bisa mengatur apakah search engine akan menampilkan nama kita atau tidak, serta memblokir akun seseorang agar tidak bisa menemukan kita di facebook.

Untuk menghindari penyalahgunaan akun facebook pada anak-anak (pelajar SD dan SMP atau baru menggunakan facebook) maka pengawasan dari pihak orang tua atau orang yang lebih dewasa dan paham tentang facebook dan dunia internet sangat diperlukan. Bagi para orang tua yang anaknya menggunakan facebook, sebaiknya orang tua ikut mendaftarkan diri menjadi pengguna facebook, dan menambahkan anaknya sebagai teman (add as friends). Dengan cara seperti ini maka aktivitas anak di facebook akan terbaca oleh orang tua melalui Newsfeed facebook. Orang tua juga dapat membuat suatu group yang dapat mewadahi anak-anaknya dan anggota keluarganya sebagai anggota group tersebut.

\section{Simpulan dan Saran Simpulan}

Berdasarkan temuan penelitian tersebut di atas, maka dapat ditarik beberapa kesimpulan sebagai berikut. Pertama, pada awalnya kehadiran situs facebook bertujuan untuk menfasilitasi pelajar di suatu universitas untuk saling mengenal dan berinteraksi. Tujuan tersebut berkembang seiring dengan perkembangan tekonologi, dimana pada 
saat sekarang tujuan utama situs facebook adalah untuk membantu penggunanya bersosialisasi ke seluruh penjuru dunia; Kedua, pada bagian kebijakan dan pengaturan privasi, facebook secara eksplisit dan imperative meminta perhatian kepada seluruh penggunanya agar berhati-hati dalam menggunakan facebook.com. Kehatianhatian tersebut terutama terkait dengan antara lain: anak dibawah umur (13 tahun) dilarang memiliki akun di facebook, para orang tua agar mengawasi aktivitas anaknya di facebook, serta kepada seluruh penggunanya diminta untuk mengatur privasi sesuai dengan kebutuhannya; dan Ketiga untuk kepentingan pelajar dan tujuan pendidikan, terdapat beberapa fitur dan aplikasi yang cocok dan sesuai adalah: group, page, serta networking. Fitur tersebut dapat dibuat dan dimanfaatkan secara maksimal untuk meningkatkan komunikasi dan interaksi di antara pelajar atau antara pelajar dengan guru.

\section{Saran}

Beberapa hal yang dapat dijadikan sebagai saransebagai berikut. Pertama, para orang tua dan guru pada jenjang Pendidikan Dasar agar mengawasi anak sekolah (terutama murid Sekolah Dasar) di bawah umur 13 tahun, tidak membuat akun di situs facebook.com. Bagi para orang tua yang anaknya sudah remaja dan membuat atau memiliki akun di facebook, diharapkan agar memberikan perhatian dan pengawasan agar tidak di salah gunakan. Kedua, bagi para pengguna facebook, terutama para pelajar agar mengatur privasi di facebook sesuai dengan tujuannya, serta memanfatkan aplikasi seperti group dan page untuk tujuan pendidikan. Ketiga, para murid, mahasiswa, guru dan dosen dapat membuat group dan page di facebook yang terasosiasi dengan sekolah dan mata pelajaran tertentu.

\section{Pustaka Acuan}

Abram. Carolyn, Pearlman. Leah. 2010, Facebook For Dummies, 2nd Edition. Indiana USA, Wiley Publishing, Inc.

Alba. Jason, Stay. Jesse. 2008, I'm on Facebook, Now What???; How to Get Personal, Business, and Professional Value from Facebook. California, Happy About Press.

Barefoot. Daren, Szabo. Julie. 2010, Friends with Benefits, A sosial media marketing handbook. San Francisci, No Starch Press.

Buckley, Clive N., Williams, Angela M. 2010, Web 2.0 Technologies for Problem-Based and Collaborative Learning. Dalam Kidd, Terry T. (Eds.). Adult Learning in the Digital Age (hlm. 118). Newyork: Information Science Reference.

Facebook's Privacy Policy; Date of last revision: April 22, 2010, http://www.facebook.com/policy.php Freishtat, Richard L., Sandlin, Jennifer A. 2010, Facebook as Public Pedagogy: A Critical Examination of Learning, Community, and Consumption. Dalam Kidd, Terry T. (Eds.). Adult Learning in the Digital Age (hlm. 148). Newyork: Information Science Reference.

http://www.insidefacebook.com

http://petamasadepanku.net

http://www.inilah.com

http://en.wikipedia.org

http://www.facebook.com

http://id.news.yahoo.com

http://en.wikipedia.org

http://www.surya.co.id

Kelsey. Todd. 2010, Sosial Networking Spaces; From Facebook to Twitter and Everything In Between. USA, Springer.

Lubis. Petti, Nugraheni. Mutia ., 2010, Kejahatan yang dilakukan wanita di Facebook. http:// id.news.yahoo.com/viva/20100422/ttc-kejahatan-yang-dilakukan-wanita-di-f-078ed6a.html.

Mahayana, Dimitri. 1999, Menjemput Masa Depan. Bandung: Remaja Rosdakarya. 
Martinez, Margaret., Jagannathan, Sheila. 2010, Social Networking, Adult Learning Success and Moodle. Dalam Kidd, Terry T. (Eds.). Adult Learning in the Digital Age (hlm. 79). Newyork: Information Science Reference.

Maver. John, Popp. Cappy., 2010, Essential Facebook development: build successful applications for the Facebook Platform. USA, Pearson Education, Inc.

Shih, Clara Chung-wai., 2009, The Facebook era: Tapping online sosial networks to build better products, reach new audiences, and sell more stuff. Boston, Prentice Hall.

Tilaar, H.A.R., 2000, Pendidikan Abad 21 menunjang Knowledge Based Economy. Jakarta: Lembaga Manajemen UNJ.

Veer. EA. Vander., 2010, Facebook; The Missing Manual $2^{\text {nd }}$ edition. USA, O'Reilly Media, Inc. 